\title{
The Potentiality of Utilizing ITS Applications in Developing the Public Transportation in Dohuk City
}

\author{
Sheimaa Ibrahim Mohammed ${ }^{1}$, Noor Akram A. Lateef ${ }^{2}$ \\ \{ sheymaa.mohammed@dpu.edu.krd ${ }^{1}$, noor.alani@dpu.edu.krd ${ }^{2}$ \} \\ 1,2 Highway and Bridges Engineering Department, Duhok Polytechnic University, Iraq
}

\begin{abstract}
The paper aims to propose an Intelligent Transportation System (henceforth ITS) applications which will work on developing public transportation (PT) in Dohuk city. This will support the transportation system economically, environmentally, socially, etc. The IVU suite, which is one of the widely used ITS applications for supporting and developing PT systems in developed countries, is proposed here for developing the PT in the study area. The study shows that the implementation of ITS in the city will give positive economic and social effects. Besides, it will reduce the economic and social losses through improving the safety and security of the roads then reducing the number of deaths and injuries caused by road accidents. As well as, improving the operation of PT system. This paper also recommends the Dohuk DoT in cooperation with the Municipality of Dohuk city to establish an information bank for road and traffic data in the city.
\end{abstract}

Keywords: Intelligent Transportation System, Public Transportation, IVU suite, ITS applications, Dohuk city.

\section{Introduction}

The use of the term Intelligent Transportation System (ITS) has emerged as a common term for what was previously known as the Intelligent Systems of Vehicles and the Road (IVHS) and Road Transport Informatics (RTI) [1]. In Europe, and sometimes both terms combined were used in Japan as Advanced Transport Telemetric (ATT). The new term is more comprehensive since it is not only used to refer to the roads and vehicles as before, but the term extends to include all related communications, management, and other systems [2]. ITS can be defined as a group of systems that rely on the use of computers, electronics, communications, and control techniques to obtain information about the performance of transport facilities, and sometimes weather and environmental conditions [3], in order to address many challenges that individuals can face during the road transportation process which will contribute into improving safety, productivity and overall mobility [4]. In Other words, ITS represents the natural evolution of the transportation infrastructure by working to re-develop the transportation infrastructures to cope with the new information generations, which will contribute to provide greater capacity and efficiency without depending on the establishment of new transportation facilities or routes [5]. The components or basic elements of ITS can be classified as [6][7]:

- Transport infrastructure such as road networks and public transport systems.

- Traffic control centers.

- Sensors and monitoring devices.

- Positioning devices and projectors in vehicles.

- Integrated communications systems.

- Basic information such as digital maps, security information, and traffic. 
Several kinds of ITS technologies were used in different countries around the world. For example, Cairo-Egypt uses intelligent transportation techniques to solve the congestion problems in the city. The wireless communication had been used to provide communication between the vehicle and the roadside such as short, medium, and long-range communications [8]. In addition, the sensing technologies had been suggested to be used in Cairo city to reduce the congestion due to the enormous increase in the number of vehicles and population that reaches approximately 7 million in 2019 [9]. One of these technologies is the pavement loops which are provided at intersections and parking entrance to sense the vehicle demand at these locations.

On the other hand, the IVU suite that had been taken into consideration in this paper as a suggestion to be implemented to develop the public transportation system in Dohuk city is considered one of the ITS applications. It is a limited liability company that was established in 1976 and its headquarter is in Berlin (Federal Germany) with branches in 7 countries: Germany, the United Kingdom, Colombia, the United Arab Emirates, Italy, Chile, and the Netherlands; with several employees that reaches about 350. The IVU suite for public transportation works on daily bases to ensure controlling hundreds of thousands of individual movements and achieve maximum efficiency [10][11]. It is considered to be an integrated solutions system provider, which supports during the past 40 years more than 500 transport companies around the world. To achieve all their requirements and objectives[12].

The IVU suite manages individual movements by taking the following tasks and actions [11]:

- $\quad$ Route planning

- Bus operation

- $\quad$ Providing passengers with information

- $\quad$ Ensure the desired inter-line connectivity

- Control traffic lights

- $\quad$ Ensuring fleet safety and efficiency

Incorporated, a one-stop approach, IVU suite provides the appropriate support for all the areas of operation related to a transportation system: from preparation, shipping, systems management, issuing tickets and passenger data to establish transport arrangements [13]. IVU suite components schedule the routes, guide passengers, maintain contacts, monitor traffic signals, manage fleets, deliver tickets, integrate information, and improve the performance. Either entire products are implemented or individual parts, IVU suite is based on open standards and can also be incorporated to the most complex system settings [10]. Several countries had adopted some of the IVU suite components for developing their public transportation systems. Turkey and Switzerland are examples of the use of IVU suite components. In Turkey, the time table component is used to create and manage the bus schedule, and this component works on: intelligent checking algorithms, Automatic conflict warnings, clearly arrange displays, integration of third-party data, and well-thought-out design [14]. While in Switzerland, the IVU crew and IVU pad are used to manage the transportation system. These components work on: powerful optimization, real-time updates, integrated payroll accounting, direct employee communication, and digital workflow [12].

\section{Proposed Intelligent Transportation System}

There are several ITS applications usually used for developing the public transportation system around the world. In this paper the researchers introduce some of the IVU suite applications as ITS techniques that are more suitable for the situation of the transportation system in Dohuk city which is discussed below:

\subsection{The public Transportation system in Dohuk city}

The transportation system in Iraq generally, and in KRI particularly, has been facing several deficiencies and shortcomings presented by the absence of the administration of the transportation system as compared with the developed countries and the increase in the number of vehicles with low road capacities. Accordingly, congestions and the large number of accidents noticed in this area. The public transport network is the arterial system of each city and town gave that mobility 
is ensured the economy will thrive and urban life flourish. However, this involves fulfilling a highly complicated array of technical, legal, and social needs. Given the rapidly expanding population and increasing urbanization, modern information technology is important to resolve these tasks.

The road system in general and public transportation in particular within Dohuk city is in a quite need to be developed through utilizing ITS techniques, which has been applied in developed countries for decades. This technology needs a system similar to mobile technology in the installation and uses in terms of infrastructure in addition to specialized units. The increase in the number of vehicles around the world prompted developed countries to find scientific mechanisms to solve the congestion called smart transport since the creation of new roads is excluded as it is very expensive.

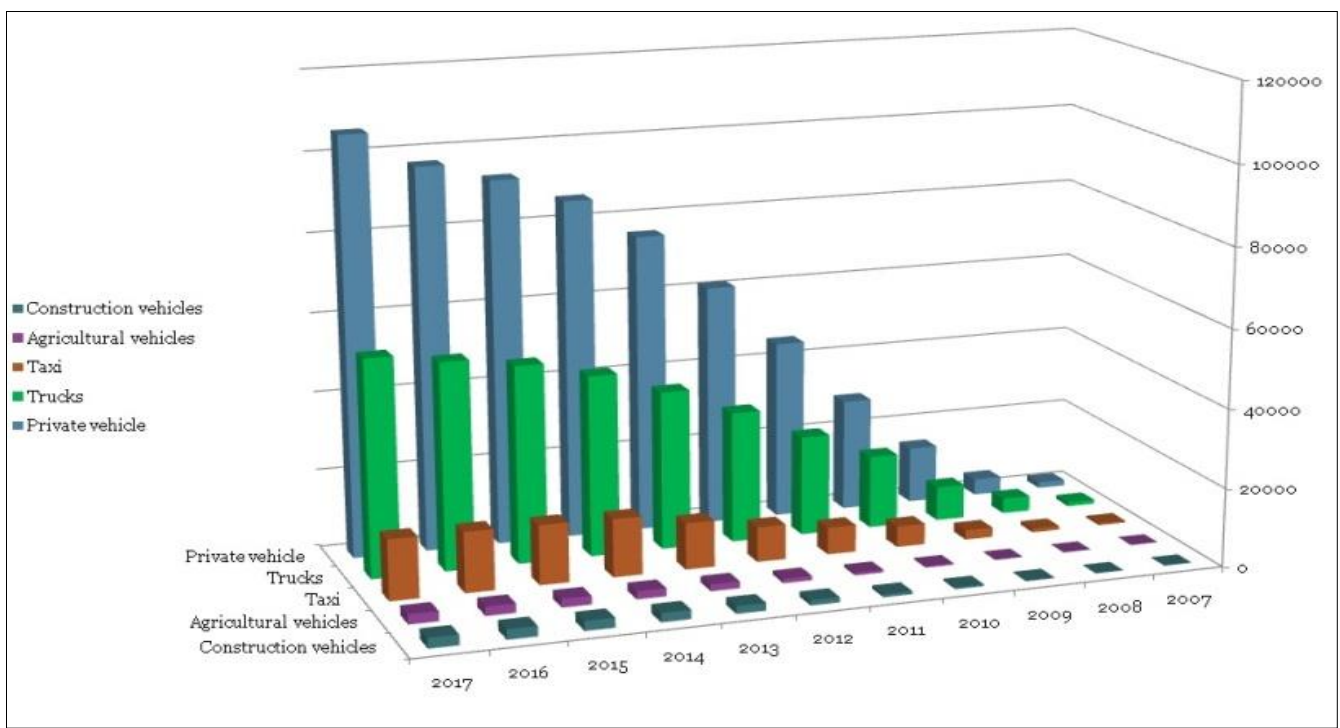

Fig. 1. Number of vehicles and their types in the city of Dohuk for the past ten years (data collected from the general directorate of traffic in Dohuk governorate)

Figure 1 shows that the population increases and their high intent to own cars act as the main cause of generating more traffic demand on the urban road networks, therefore, Duhok City transportation network is dealing with an explosive use of private cars for transporting purposes that lead to increase the congestion in the city and hence increase the delay time and vehicle emissions. Poor quality and non-convenience public transportation facilities in the study area lead the passengers to reduce the use of public transporting and increase the use of private cars and taxies, see Figs. 2 and 3.

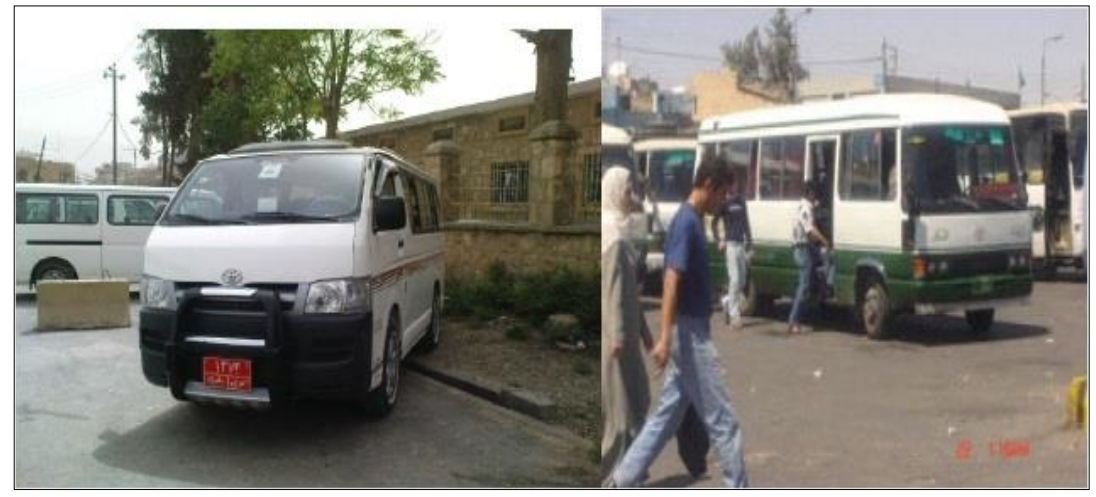

Fig. 2. Poor quality and non-convenience public transportation facilities 


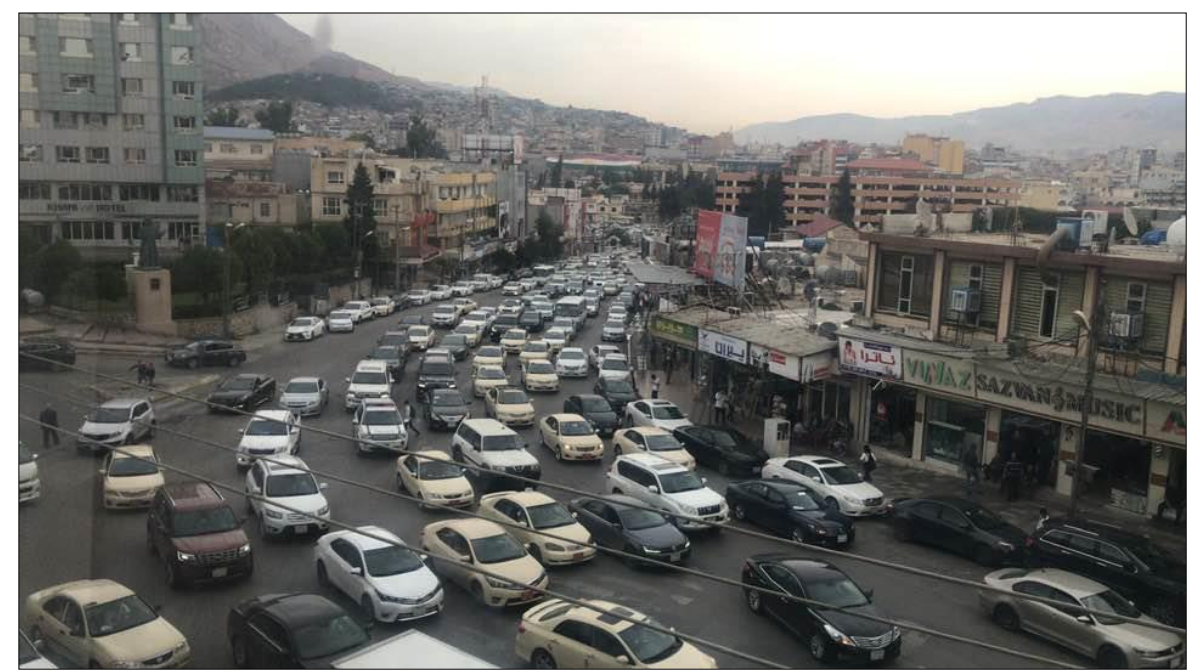

Fig. 3. Taxis and private cars congestion in Dohuk city local Bazar

\subsection{Proposed software package IVU suite}

IVU Suite as mentioned is a limited responsibility company and it specifically depends on good cooperation with the IT system different users in the transportation companies, in other meanings, with people planning, implementing, and bill paying the public transportation by buses and rails [15]. A logical implication enables better communication. With more than 40 years, IVU has produced software systems for transportation companies. But it still does have a particular appeal, creating a unique challenge: requesting optimized procedures, digital map displays, wireless technology, and also on-board electronics. In addition to monitoring vehicle movements in current operations, these are all elements of the public transport IT network [8][15]. For that IVU suite can achieve its objectives and achieve the optimum level of transport, it has relied on several tools and programs which will be discussed in detail as follows:

1. IVU suite tools to achieve the optimum level of transportation in Duhok city: To achieve its objectives, many tools that adopted for IVU suite must be used which are:

2. Combining mathematical research with engineering skills and expertise: As the improvement process means achieving the best possible result, taking into account all the requirements, if only the shortest path between two points was needed, the solution would be simple. While finding the fastest route connecting many points with different conditions is considered a very complex computation task, as multi-layered tasks and decision-making processes can be implemented with the help of information technology and mathematics only.

3. Issue time schedules and work plans of vehicles which will be operated within the city of Dohuk and that will be according to the number of passengers expected and specifications of vehicles and frequencies.

4. Define task lists and enable task re-scheduling based on the rules and capabilities of different groups of individuals and warehouses.

5. IVU suite programs for public transportation to achieve an optimal level of transportation in Duhok city: For the reason of improving and developing the transportation sector, the IVU suite has developed many products, media, and electronic programs [15]. In turn, possible use of some of these technologies and to develop and improve the transport sector in the city of Duhok, including:

- IVU Cockpit: It is a portable software on board of a vehicle that can be operated using IVU Ticket Box, laptops, or electronic devices such as smartphones, as shown in figure 4. This software shows the current location of the drivers, their progress according to the schedule, providing information to the passengers, and organizes mutual contact with the control center.

- IVU Ticket Box: It is a user-friendly device that is installed on buses or trains. This device 
is based on modular components and has an interface for all communication systems, location identification (GPS), Wireless and analog communication, and digital cell phone, as shown in Fig. 4. This controls the entire vehicle environment as well as the ticket vendors. It is a system that supports all forms of electronic ticket management control [11].

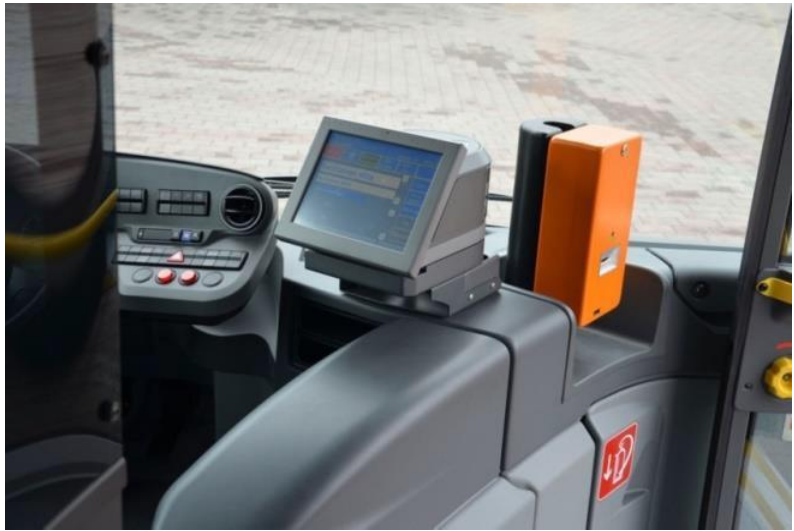

Fig. 4. IVU ticket box and IVU cockpit software[16]

- IVU Validator: An electronic ticketing device, designed to be used as a ticket control device when entering the vehicles or as a stand-alone sales agency, as shown in Fig. 5. The user interface provides ease of dealing with optional touch technology [8].

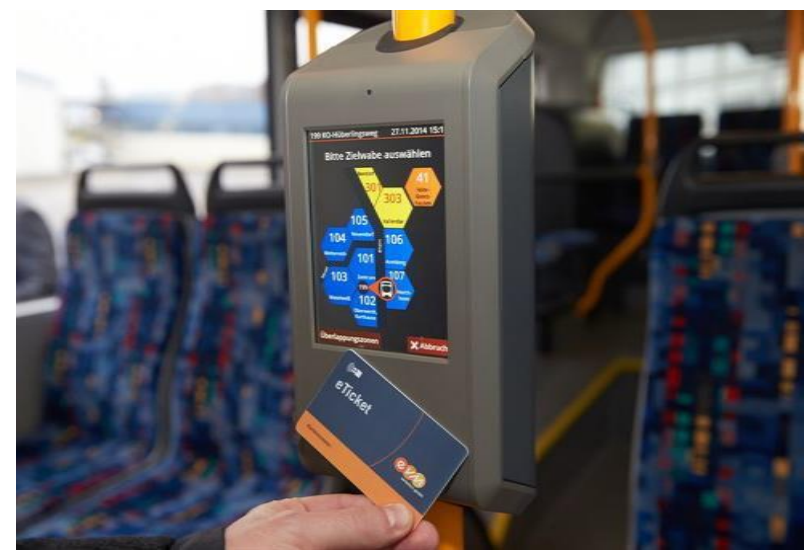

Fig. 5. IVU Validator [12].

- IVU Realtime: It enables passengers to see the control center directly. Its function is to handle all incoming information to the control center and then display it to passengers in a variety of media, as shown in Fig. 6. It also displays information directly on mobile devices so that the waiting time of the passengers will pass faster than it actually is which keeps them away from getting bored and makes them spend their time in a fun way because they are reassured by this tool [11]. 


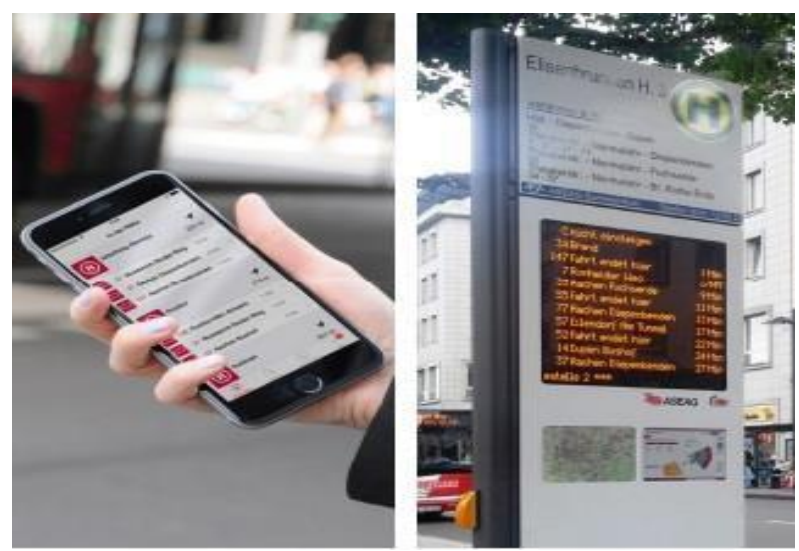

Fig. 6. IVU Realtime [12]

- IVU FLEET: It can identify and follow the data of the vehicles in the city at all times. It will also work to display data on a Duhok digital map that includes the current traffic situation in the city, the location of all vehicles, and all disturbances if they exist or arise immediately. Additionally, it will provide multi-layer functions and controllers with effective solutions, as well as monitoring the implementation of those solutions, ensuring the ability to connect to all vehicles and record their movements [17].

- IVU CREW: It controls the management of all staff scheduling matters from the planning of long-term holidays to the allocation of daily tasks and the calculation of wages [15].

\subsection{IVU Implementation Requirements in Duhok City}

For implementing the IVU suit to develop the public transportation system in Dohuk city there are several requirements consider for such kind of intelligent systems, below is a bunch of them:

\section{Information collection methods:}

Firstly: collecting the traffic information by putting sensors in specific places of Duhok roads and intersections and the vehicles as well to obtain the numbers of private cars and vehicles and to know the condition of roads at peak hours, in order to benefit from the traffic management and to reduce traffic congestion in the city where it will be linked to smart traffic signs. Considering another benefit from this collected information in the evaluation of methods at the short-term level and the level of strategic studies as plans for the development of transportation in Duhok. Besides, collecting the information required about the vehicle's movements and their schedule provides a distinct future service for users.

Secondly: using specialized cameras on the traffic side and that can be installed in the advanced stages of this project if needed. The information that is recorded by these cameras is used to evaluate some characteristics of the roads and intersections (like flow, delay, and density) as well as the safety of roads, security situation, and control violations, and others.

II. Data processing techniques: These technologies include software and devices that can be used to convert those data into information used by the road user (drivers and passengers), for instance, in the case of congestion to reduce the speed limits or change the path of the vehicles from the busy track.

III. Control techniques: which include traffic signals, guidance, and warning signs, co-ordinations with public transportation facilities, and offices based on various transportation activities. In addition to the establishment of control rooms and banks of traffic and transport information.

IV. Systems and techniques: there should be a plan to use an integrated system for managing various 
transportation activities and provide extensive services to users of this system. It is possible to use global management systems such as the Advanced Traffic Management System (ATMs) and the Advanced Traveler Information System (ATIS).

On the other hand, there will be several challenges facing the application of this kind of Intelligent Transportation Systems to support and develop public transportation in Dohuk city, which are:

1) Deficiency in skills and resources to maintain and operate technologies adopted by the ITS.

2) Deficiency in the internal technical capacity to process, understand, and analyze the collected data.

3) Unavailability of the advanced analytical solutions for the industry of public transportation.

4) Lack of information and knowledge of the ITS systems and abilities, which will reduce the capability to specify the best condition when contracting with the suppliers.

5) Lack of understanding among the suppliers regarding the specific needs of public transportation and that will strongly affect the efficiency of the final product.

\section{CONCLUSION}

This study drew the following conclusions:

1) The application of the ITS to support public transportation in Dohuk city will give positive economic and social effects.

2 ) Intelligent transport systems implement various available smart technologies, such as eclearance for public vehicles and automated road safety inspection, which improves the safety and efficiency of public transport vehicles (buses and mini-buses).

3 ) The implementation of the ITS will reduce the magnitude of economic and social losses by reducing the number of deaths and injuries caused by road accidents.

4) The previous conclusion leads to improving the safety and security of the roads and improve the operations of public transport.

5 ) Intelligent transport has also contributed to increasing emergency event management by providing highly efficient intervention procedures in cases of emergency traffic, adverse weather conditions, and road works.

6) The advanced technologies used in intelligent transport systems focus on sensing the presence of accidents, which in turn, improves the response time and sends the appropriate teams in terms of personnel and equipment.

7) Increase the ability to manage the demand for mobility through the implementation of the system.

8) Speed regulations, the distances among vehicles in each lane and the automatic controlling o f motion within vehicles, all affect and improve road efficiency as well as enhance the traffic flow rate.

9) The ITS provides road users (drivers) the ability to access, analyze, and present the available information in order to help them move from their place of departure to the destination they wish to reach.

10) In this regard, intelligent transport systems provide such assistance in the best way possible, through providing the safety, comfort, and minimization of the effects of road transport on the environment and energy by minimizing harmful emissions from vehicles, minimizing wasted fuel due to overcrowding, failure to choose the right route, minimizing noise pollution and harassing traffic to residential areas, as well as reducing of the consumption of harmful substances to the environment.

\section{RECOMMENDATIONS}

After considering the reality of the public transportation system in Dohuk city and the proposed Intelligent Transportation System (IVU suite) to be applied for developing the status of 
the public transportation, the below recommendations are provided by the researchers to prepare the transportation system for the applications of the ITS in the city same as in the developed countries:

1) The public transportation in Dohuk city needs to be developed to support the transportation system in the area economically, environmentally and from all other aspects.

2) A rapid application of the proposed Intelligent Transportation system is recommended in line with the global trend of ITS application at the state, regional, and city levels.

3) The Directorate of Transportation in Dohuk city should prepare programs and awareness sessions on the importance of the smart transportation systems to sustain the economy, construct a structural plan for public transportation in Dohuk city, and the problems facing it.

4) Develop a strategic plan in Dohuk city to implement the ITS application, and that the implementation should be on stages starting from Dohuk city, then when the project will succeed to expand the system to the whole Dohuk governorate, or maybe to all KRI.

5) Training and recruiting of the technical staff who are specialized in intelligent management, Data management, and traffic engineering.

6) Co-operation process between the Directorate of Transportation with the Municipality of Dohuk city to establish an information bank for roads and traffic data in Dohuk city related to road transportation.

7) The study highlighting the need to encourage investment in ITS projects which will serve and develop the transportation system in Dohuk city. In addition to organize workshops and extensive meetings to raise awareness regarding the importance of investing within the sector of Intelligent Transportation Systems.

\section{REFERENCES}

[1] Iiles, R.: Public Transport in Developing Countries, 1st ed. London: Elsevier, 2005.

[2] Ghamidi, A.S.: Basic concepts in traffic science. Al-Riyadh, 1999.

[3] Mathew, T.V.: Chapter 48 Intelligent Transportation System - I. Tansportation Syst. Eng., no. 1999, pp. $1-22,2014$.

[4] Bolquas, I.: Intelligent transport systems technology as a strategy for the development of the transport sector. Econ. Vis., no. 6, 2014.

[5] Wootton, J.R., García-Ortiz, A., Amin, S.M.: Intelligent transportation systems: A global perspective. Math. Comput. Model., vol. 22, no. 4-7, pp. 259-268, 1995.

[6] Mohan, D.: Intelligent Transportation Systems ( ITS ) and the Transportation system. Transp. Res. Inj. Prev. Program., no. March 2015, pp. 1-15, 2015.

[7] Elhusseiny, H.: The Opportunities and Challenges of Applying the Intelligent Transport Systems on Road Transport in Egypt: A Case Study of, 2016.

[8] Radwan, A.H. "Intelligent transportation system as tool in solving Cairo's transportation problems," Int. J. Sci. Eng. Res., vol. 6, no. 11, pp. 1160-1172, 2015.

[9] "World O meters," 2019. [Online]. Available: https://www.worldometers.info/world-population/egyptpopulation/.

[10] Müller, M., Bergstein, H., and Kochanski, F.: IVU.Suit for Public Transportation. 2012.

[11] Elschner, M., Rust, M. and Struijk, L.: Annual Report 2017,” Berlin, 2018.

[12] IVU Traffic Technologies. IVU suite for public transportation. Berlin, Germany, 2012.

[13] Steck, S.: IVU NEWS NEXT STOP : THE FUTURE. 2018.

[14] Langenhan, A. : VU Planning Systems. 2011.

[15] Scholz, G.: IT system in Public Transport. Berlin, Germany, 2017.

[16] IVUTraffic Technologies. IVU.Box. 2018. [Online]. Available: https://www.ivu.com/ivusuite/fleetmanagement/ivubox.html. [Accessed: 25-Dec-2019].

[17] IVUTraffic Technologies, IVU.FLEET. 2018. [Online]. Available: https://www.ivu.com/ivusuite/fleet-management/ivufleet.html. [Accessed: 20-Dec-2019]. 